\title{
Internet y actividades terroristas: el caso del 11-M
}

\author{
Por Javier Jordán y Manuel R. Torres
}

\begin{abstract}
Resumen: Se estudian las diversas funciones que desempeñó internet en la actividad de los terroristas de los atentados del 11 de marzo de 2004 en Madrid, utilizando como principal fuente el análisis de los ordenadores y memorias extraíbles incautados por la policía española. Este caso de estudio se pone en relación con los marcos explicativos existentes al respecto en la literatura especializada sobre la relación entre terrorismo e internet.
\end{abstract}

Palabras clave: Informática forense, Terrorismo, Propaganda, Inteligencia criminal.

\section{Title: The internet and terrorist activities: the case of $3 / 11$}

Abstract: This article analyses the internet functionality used by the terrorists responsible for the Madrid bombings of March 11, 2004. The computers and USB memory drives seized by the Spanish police form the main source for the analysis. This case study is contrasted with the contemporary theoretical framework of the relation between terrorism and the internet.

Keywords: Computer forensics, Terrorism, Propaganda, Criminal intelligence.

Jordán, Javier; Torres, Manuel R. "Internet y actividades terroristas: el caso del 11-M". En: El profesional de la información, 2007, marzo-abril, v. 16, n. 2, pp. 123-130.

DOI: 10.3145/epi.2007.mar.04

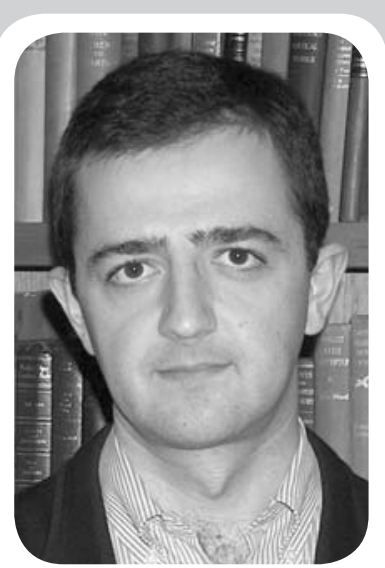

Javier Jordán es profesor del Departamento de Ciencias Políticas y de la Administración de la Universidad de Granada (España), del Instituto Andaluz de Criminología y experto en servicios de inteligencia del Instituto Universitario "General Gutiérrez Mellado". Es también redactor jefe de ihadMonitor.org.

\section{Introducción}

Desde hace algunos años los grupos violentos de inspiración yihadista vienen haciendo un uso intensivo de internet con fines de captación, propaganda, adoctrinamiento, comunicación interna, financiación ilícita, apoyo operativo y (en casos excepcionales) como medio de ataque cibernético. Se trata además de una tendencia al alza, pues aunque las agencias antiterroristas también persiguen las actividades de los radicales en el ciberespacio, en la práctica, la Red ofrece a los terroristas un amplio abanico de posibilidades difíciles de contrarrestar.

El grupo terrorista que ejecutó la masacre de los trenes el 11 de marzo de 2004 en Madrid (11-M) también utilizó internet en los meses previos a los atentados y en las semanas posteriores a ellos, hasta que el núcleo principal de la red se suicidó al verse rodeado por la policía el 3 de abril en un piso de la localidad madrileña de Leganés. El propósito de este artículo consiste en analizar pormenorizadamente las funciones que desempeñó internet en la actividad de estos terroristas.
La fuente principal de nuestra investigación es el Auto de procesamiento 20/04. En él se dedican más de ciento veinte páginas a analizar el contenido de los discos duros, cds y memorias extraíbles utilizados por los miembros más destacados del grupo. Desafortunadamente el informe policial inserto en el auto no recoge el contenido íntegro de los cientos de archivos hallados. Al mismo tiempo, decenas de direcciones de internet visitadas por los terroristas dejaron de encontrarse disponibles meses más tarde, cuando los especialistas del Cuerpo Nacional de Policía siguieron el rastro de las cookies alojadas en los ordenadores. Pero, a pesar de estas carencias informativas, los datos que ofrece el análisis policial son suficientemente abundantes como para considerarlos una muestra representativa de los contenidos visualizados por los yihadistas. Por otra parte, el auto de procesamiento recoge numerosos testimonios de testigos protegidos, cartas manuscritas y resultados de vigilancias policiales, donde también se refleja el uso de internet por los terroristas del 11-M.

El empleo de documentos judiciales es una práctica habitual en los estudios sobre terrorismo, que plantea 
ventajas e inconvenientes. La principal ventaja consiste en que ofrecen una visión cercana y detallada del comportamiento de los imputados, difícilmente obtenible por otro tipo de fuentes. El problema se encuentra en que los sumarios y autos de procesamiento sólo recogen la argumentación de una de las partes, la del juez instructor y de los peritos policiales. Por ello suele ser preferible metodológicamente utilizar la sentencia condenatoria como documento más contrastado y fiable. No obstante, consideramos que en el caso de nuestro estudio el auto de procesamiento constituye una fuente solvente ya que el informe policial que analiza el contenido de los ordenadores y memorias extraíbles es suficientemente riguroso como para obtener las conclusiones que desarrollamos en nuestro artículo. Además, no hay que olvidar que dichos elementos fueron utilizados por personas que cometieron un acto de suicidio colectivo tras varias horas de asedio policial y que son multitud las pruebas que avalan su militancia yihadista y su implicación directa en los atentados de Madrid.

Además de esta fuente judicial, hemos utilizado numerosos artículos y libros de la literatura especializada sobre terrorismo que nos han permitido reforzar y contrastar teóricamente nuestros análisis y conclusiones. La bibliografía de este artículo incluye sólo una selección de los mismos.

En los siguientes epígrafes se revisará cada una de las funciones que desempeñó internet en la actividad del grupo terrorista de Madrid y que han sido categorizadas de la siguiente manera: a) adoctrinamiento ideológico, b) refuerzo emocional, c) adiestramiento, e) obtención de información operativa, f) comunicación privada, g) comunicación pública y propaganda, y h) seguimiento del impacto mediático de sus acciones.

Como puede observarse hemos dejado fuera de nuestro análisis otras posibilidades y que en el caso concreto del 11-M, y de la mayoría de grupos yihadistas se encuentran ausentes, pues hasta el momento constituyen funciones excepcionales. Se trata del reclutamiento directo, de la financiación ilícita y de la posibilidad de llevar a cabo ataques cibernéticos. Antes de pasar al análisis del grupo de Madrid conviene que comentemos muy brevemente estas tres funciones con el fin de ofrecer en este artículo una visión global del rol que cumple internet para los yihadistas.

El reclutamiento directo a través de la Red (es decir, la radicalización e ingreso de un individuo en un grupo yihadista sólo por la consulta de sitios web y la participación en foros radicales) es hasta al momento una posibilidad y no consta que se haya producido. Internet juega un papel muy relevante pero de refuerzo, unido a otros factores y procedimientos de captación. El estudio de los perfiles de individuos radicalizados demuestra que en la inmensa mayoría de los casos la captación se produce sobre todo a través de la amistad y del trato personal (Sageman, 2004, p. 91). El "ciber-reclutamiento", si ha llegado a producirse en algún caso, es una anomalía (Burton, 2006).

La financiación ilícita a través de internet es una práctica generalizada mediante técnicas como el phising, la captura y fraude con los números de tarjetas de crédito, las subastas y ventas falsas de productos, o diferentes tipos de timo mediante correos spam. Sin embargo, por ahora no hay pruebas de que estos sistemas representen una actividad preferente de los grupos yihadistas. $\mathrm{Su}$ financiación mediante actividades delictivas se centra en prácticas más tangibles como el comercio de droga, el fraude con tarjetas de crédito robadas o duplicadas y los pequeños robos.

Por último, la ejecución de ataques cibernéticos contra infraestructuras vitales (por ejemplo, sistemas informáticos de compañías de electricidad, aeropuertos o centros financieros) continúa siendo una amenaza inquietante pero, por el momento, tampoco se ha materializado. Se han encontrado rastros de visitas e intentos de acceso a ese tipo de infraestructuras estratégicas norteamericanas en ordenadores capturados a yihadistas en Pakistán o en EUA, pero sin mayores consecuencias. Se trata de sistemas robustos y muy difícilmente penetrables. Por ese motivo los ataques informáticos de los simpatizantes con el yihadismo se han limitado a colapsar los servicios de sitios web de instituciones o de empresas vinculadas a EUA e Israel. En realidad ese tipo de prácticas más que "ciberterrorismo" podrían ser catalogadas como "ciberactivismo" (Dening, 2001).

Pasamos a continuación al análisis del empleo de internet por parte del grupo terrorista del 11-M.

\section{Adoctrinamiento ideológico}

La principal función que cumplió la Red consistió en apoyar al adoctrinamiento ideológico del grupo. Es la conclusión a la que lleva el análisis de los 186 archivos hallados y descritos en el informe policial incluido en el Auto de procesamiento 20/04. La mayoría de esos archivos (tanto de audio como de texto) contienen enseñanzas de carácter político-religioso, en su mayoría abiertamente radicales. Como muestra el gráfico 1, de 186 archivos sólo 19 documentos son manuales operativos (y con las salvedades que posteriormente veremos); todos los demás se dedican al adoctrinamiento ideológico.

Internet facilita enormemente la adquisición de artículos y libros de carácter radical, así como la audición de sermones pronunciados en entornos clandestinos. Sin el acceso a través de la Red, la obtención de ese tipo de materiales resultaría mucho más compleja, lenta e 


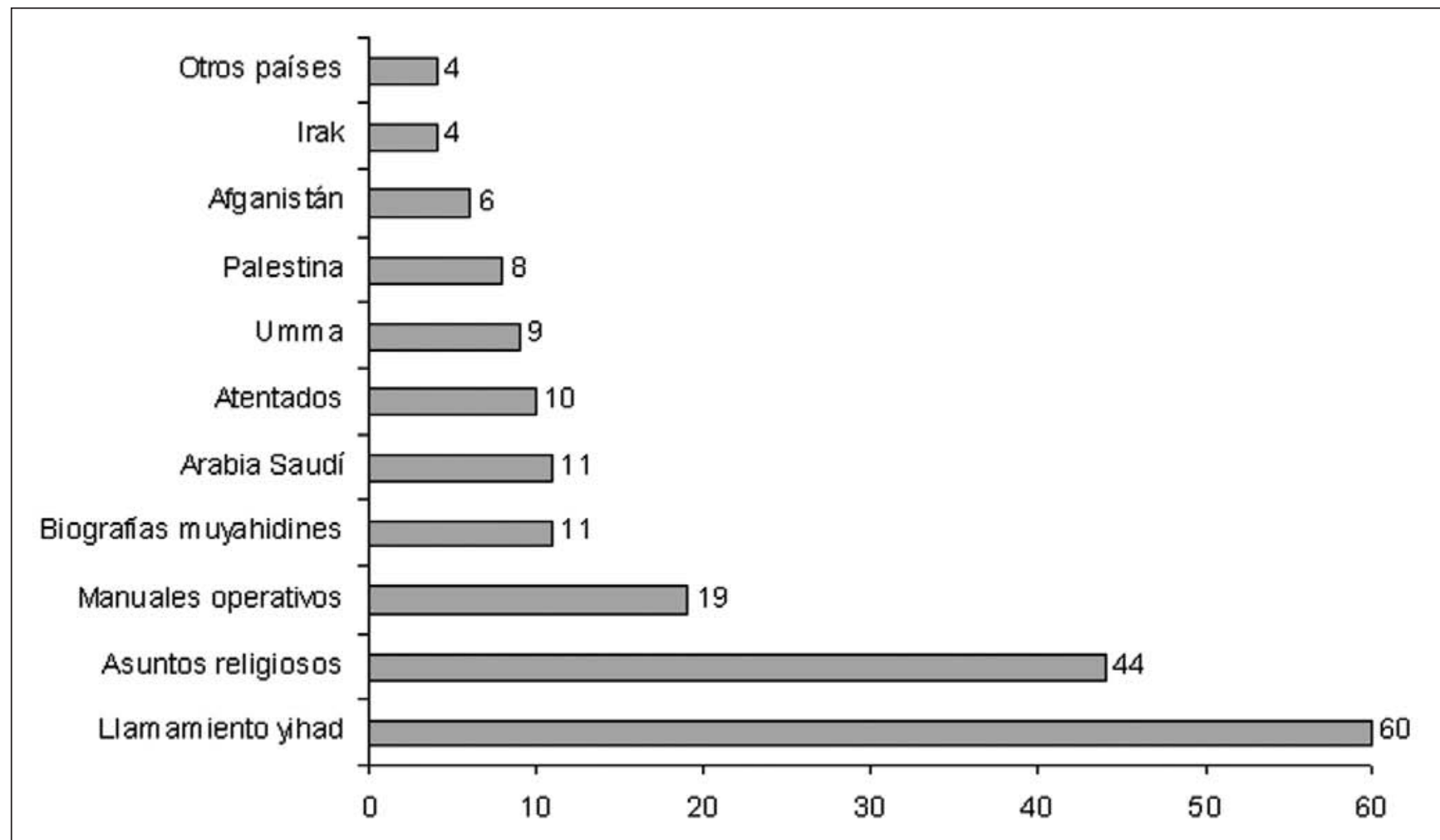

\begin{tabular}{|c|c|}
\hline Llamamiento yihad & $\begin{array}{l}\text { Se justifica la yihad armada, se hace un llamamiento a los musulmanes para que } \\
\text { emprendan esta lucha o se legitima el terrorismo como un mandato religioso. Se } \\
\text { identifica como enemigos a los gobernantes de los países de mayoría musulmana y } \\
\text { a los gobiernos y sociedades occidentales. }\end{array}$ \\
\hline Asuntos religiosos & $\begin{array}{l}\text { Contenido puramente religioso, colecciones de hadices, o documentos sobre juris- } \\
\text { prudencia islámica. }\end{array}$ \\
\hline Manuales operativos & $\begin{array}{l}\text { Ensayos sobre estrategia y tácticas militares e información de carácter técnico sobre } \\
\text { armamento y explosivos. }\end{array}$ \\
\hline Biografía muyahidines & $\begin{array}{l}\text { Se elogia a los combatientes islámicos o se rememora su biografía y sus actos "he- } \\
\text { roicos". }\end{array}$ \\
\hline Arabia & $\begin{array}{l}\text { Reflexiones sobre la necesidad de emprender la yihad contra la monarquía de Arabia } \\
\text { Saudí y donde se teoriza sobre el carácter ilegítimo de su clase gobernante. }\end{array}$ \\
\hline Aten & $\begin{array}{l}\text { Documentos escritos o audiovisuales donde se recogen acciones terroristas, o se } \\
\text { elogia a sus autores. }\end{array}$ \\
\hline Umma & $\begin{array}{l}\text { Reflexiones sobre el estado general de la comunidad musulmana y el origen de sus } \\
\text { problemas. }\end{array}$ \\
\hline Palestina & $\begin{array}{l}\text { Se justifica la yihad en Palestina, la lucha contra Israel o se recoge información so- } \\
\text { bre la tragedia del pueblo palestino. }\end{array}$ \\
\hline Afganistán & $\begin{array}{l}\text { Se elogia la primera yihad en Afganistán (contra los soviéticos) o se establece la } \\
\text { necesidad de una nueva yihad (contra las tropas norteamericanas). }\end{array}$ \\
\hline Irak & $\begin{array}{l}\text { Se reflexiona sobre los sufrimientos del pueblo iraquí y las consecuencias de la ocu- } \\
\text { pación americana. }\end{array}$ \\
\hline Otros & $\begin{array}{l}\text { Situación de la comunidad musulmana en otras regiones distintas a las menciona- } \\
\text { das. }\end{array}$ \\
\hline
\end{tabular}

Gráfico 1. Contenido temático de los archivos

insegura (Weimann, 2006). Nuestro análisis coincide con el de la literatura especializada que también destaca la enorme importancia de internet como instrumento de difusión global del yihadismo (Scheuer, 2004, pp. 78-84; Gunaratna, 2004; Kohlmann, 2006). Al-Qai$d a$ ha logrado poner en marcha un movimiento ideoló-
“La principal función que cumplió internet consistió en apoyar al adoctrinamiento ideológico del grupo" 


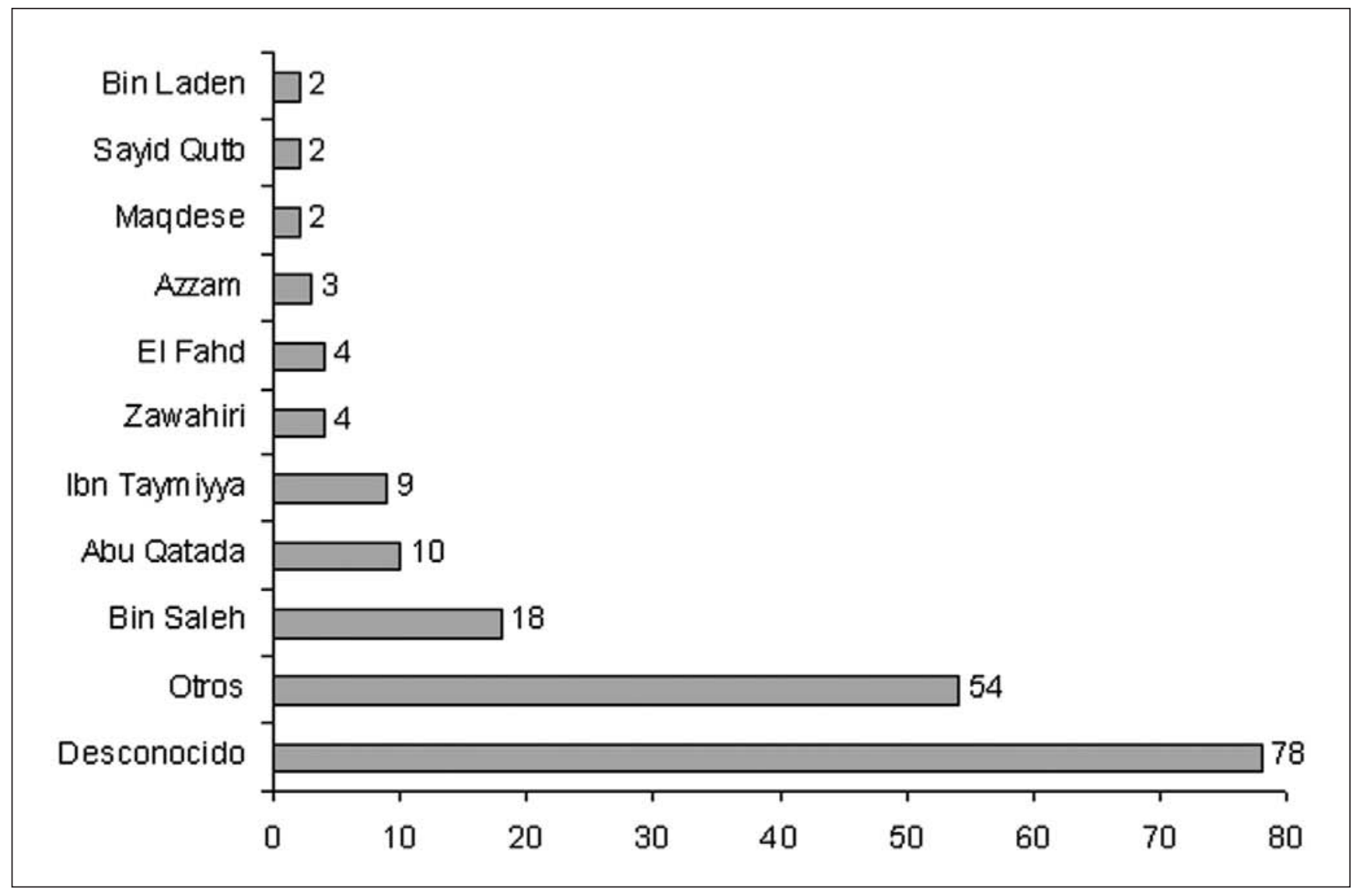

\begin{tabular}{|c|c|}
\hline Bin Laden & Osama Bin Laden. Saudí, líder y fundador de al-Qaida. \\
\hline Qutb & $\begin{array}{l}\text { Sayid Qutb. Pensador egipcio ejecutado en } 1965 \text {. Ideólogo de referencia de los yihadis- } \\
\text { tas. }\end{array}$ \\
\hline Maqdese & $\begin{array}{l}\text { Jeque Abu Mohammed al-Maqdese, ideólogo de la corriente takfirí (la más extrema } \\
\text { dentro del yihadismo). De origen palestino, ha ejercido una enorme influencia intelectual } \\
\text { sobre importantes terroristas como el líder de Al Qaeda en Irak, Abu Musab al-Zarqawi. } \\
\text { En la actualidad se encuentra en prisión en Jordania. }\end{array}$ \\
\hline Azzam & $\begin{array}{l}\text { Abdullah Azzam. De origen palestino, mentor de Bin Laden y fundador de la Oficina de } \\
\text { Servicios Afganos (la organización que reclutó a miles de voluntarios para combatir a los } \\
\text { soviéticos y que más tarde acabó siendo asumida por Al-Qaida). }\end{array}$ \\
\hline El Fahd & $\begin{array}{l}\text { Nassar Bin Hamad el Fahd. Joven jeque saudí. Se hizo famoso en } 2003 \text { al promulgar } \\
\text { una fatua (sentencia jurídica) donde dotaba de legitimidad religiosa al uso de armas de } \\
\text { destrucción masiva contra no musulmanes. }\end{array}$ \\
\hline Zawahiri & $\begin{array}{l}\text { Ayman Al Zawahiri. Líder del grupo terrorista egipcio Tanzim al-Yihad y número dos de } \\
\text { al-Qaida. }\end{array}$ \\
\hline Ibn Taymiyya & $\begin{array}{l}\text { Ibn Taymiyya. Pensador musulmán de origen sirio que vivió entre los años } 1263-1328 \text {. } \\
\text { Algunos de sus argumentos sobre el yihad armado y la relación entre política y religión han } \\
\text { inspirado a los pensadores yihadistas contemporáneos. }\end{array}$ \\
\hline Abu Qatada & $\begin{array}{l}\text { Abu Qatada. Su verdadero nombre es Omar Othman. De origen palestino vive en Lon- } \\
\text { dres desde 1994. Está considerado como el líder ideológico de Al-Qaida en Europa. }\end{array}$ \\
\hline Bin Saleh & $\begin{array}{l}\text { El jeque egipcio Abdul Aziz Bin Saleh, también conocido como Abdul Kader Abdul Aziz, } \\
\text { es uno de los principales ideólogos de la corriente takfirí con libros tan señalados para esta } \\
\text { doctrina como: "Necesidad u obligación de la emigración de la tierra de los no creyentes a } \\
\text { la tierra del Islam". }\end{array}$ \\
\hline Otros & $\begin{array}{l}\text { En este apartado se incluyen los documentos elaborados por más de una treintena de auto- } \\
\text { res individuales (mayoritariamente saudíes, egipcios y marroquíes), junto a los materiales } \\
\text { difundidos por organizaciones yihadistas como Ansar al-Sunnah, Al Qaida en Arabia Saudí } \\
\text { o la rama mediática de al-Qaida: Sahab Intitute for Media Production. }\end{array}$ \\
\hline Desconocido & $\begin{array}{l}\text { Documentos anónimos/desconocimiento de su autoría. En el caso de predicadores se trata } \\
\text { de personas en su mayoría con acento saudí y algunos otros con acento marroquí. }\end{array}$ \\
\hline
\end{tabular}

Gráfico 2. Autores de los documentos o sermones hallados 
"Al-Qaida ha logrado poner en marcha un movimiento ideológico transnacional con un alto grado de descentralización"

gico transnacional con un alto grado de descentralización y, en gran medida, su fuerza radica en la capacidad de diseminar sus ideas. De ese modo, la función que cumple la propaganda radical puede ser resumida en los siguientes puntos:

- Proporciona un cuerpo teórico de razonamientos y de valores dotado de coherencia interna. En consecuencia:

- Legitima religiosamente las acciones terroristas por la repetición insistente de que los yihadistas están combatiendo una guerra defensiva en inferioridad de condiciones, y que al hacerlo cumplen una obligación moral.

- Permite que los simpatizantes del yihadismo, y en especial los reclutadores y líderes, utilicen argumentos político-religiosos para atraer a otros hacia su causa. En muchos casos los potenciales reclutas son personas con escasa formación religiosa que quedan asombrados por la "erudición" religiosa de los más comprometidos. Por ejemplo, la declaración de un individuo que asistió a las reuniones privadas del grupo de Serhane AbdeImajid "el tunecino" constata la autoridad moral que este sujeto tenía entre sus seguidores debido a su superior formación religiosa y académica. En cierto modo internet facilita la adquisición de esos conocimientos a través de la formación a distancia.

- Contribuye a que los individuos inmersos en la subcultura yihadista no se perciban a sí mismos como sujetos aislados, sino como miembros de una comunidad global mucho más amplia que goza de la sanción legal y religiosa de expertos en ciencias islámicas (Allevi, 2003). El gráfico 2 muestra la gran variedad de autores de los documentos doctrinales y sermones contenidos en la muestra de nuestro estudio. Esa diversidad constituye un indicio de la asiduidad con que algunos los miembros del grupo visitaban sitios web yihadistas y del tiempo que invertían en ello.

\section{Refuerzo emocional}

Otra de las funciones que cumple internet consiste en la transmisión de archivos de imagen, audio y vídeo que refuerzan el adoctrinamiento ideológico, el sentido de pertenencia y, especialmente, suscitan lo que el sociólogo francés Farhad Josrojavar (2003, p. 238) denomina frustración delegada; es decir, la rebelión ante injusticias que sufren otras personas.
La propaganda yihadista procura estimular ese tipo de sentimientos difundiendo imágenes desgarradoras de mujeres y niños musulmanes muertos o heridos; soldados israelíes maltratando a jóvenes palestinos; efectos de bombardeos norteamericanos sobre población civil, etc. La red del 11-M tenía archivos de ese tipo en sus ordenadores. También consta que desde ellos visitaron sitios web yihadistas donde aparecían imágenes de similares características. Sin embargo, la muestra de archivos hallados y analizados por la policía sólo contiene una pequeña fracción de ellos: $8 \%$ de vídeo, $19 \%$ de audio y $73 \%$ de texto. Los que aparecen catalogados como audio se refieren en su mayoría a sermones de predicadores radicales.

Esto no quiere decir que los yihadistas del 11-M tuvieran una escasa cultura o gusto por la imagen. La declaración de varios testigos protegidos deja constancia de reuniones en las que Serhane Abdelmajid, Moutaz Almallah Dabas, Mustafa El Maymouni o Jamal Ahmidan (cuatro miembros destacados del grupo de Madrid) proyectaban en sus ordenadores vídeos con imágenes de injusticias sufridas por musulmanes. Por ejemplo, la mujer de Mouhannad Almallah Dabas habla de un vídeo donde unos soldados rusos (seguramente en Chechenia) matan a sangre fría a una familia musulmana y pasan por encima de cuerpos de civiles con un carro de combate.

Por tanto la escasez de contenidos audiovisuales y el reducido número de documentos que hacen referencia a Irak (gráfico 1) podría explicarse de dos maneras: que habría más archivos pero no están incluidos en la muestra de nuestro estudio o (más posiblemente) que no es hasta mediados de 2004 cuando se produce la eclosión propagandística de los grupos yihadistas en Irak (con la producción de cientos de comunicados y archivos audiovisuales). Los atentados de Madrid se cometieron en el primer tercio del año y muchos de los documentos hallados habían sido descargados el año anterior.

Otra función de ese tipo de documentos gráficos y audiovisuales consiste en insuflar moral mostrando imágenes de atentados o de combates en vivo, así como de los "trofeos" y de las consecuencias de sus acciones. Entre los archivos encontrados a los terroristas del 11- 
M están por ejemplo vídeos de ataques a las fuerzas norteamericanas en Irak, profanaciones de cadáveres, imágenes de la documentación de uno de los miembros del CNI asesinados en Irak, etc. Ese tipo de materiales resultan complementarios con los de adoctrinamiento ideológico en la creación de la comunidad transnacional yihadista a la que antes aludíamos.

\section{Adiestramiento}

Una tercera función es la transmisión de know-how terrorista. Desde cómo llevar a cabo secuestros y fabricar explosivos, hasta cuál debe ser el comportamiento en caso de ser detenidos por la policía. Evidentemente este tipo de documentos no sustituyen el adiestramiento en la vida real, mediante la repetición de los procedimientos de inteligencia, seguridad en las operaciones o preparación de atentados, pero en casos concretos pueden ser de gran utilidad. Por ejemplo, los terroristas de los atentados de Londres, el 7 de julio de 2005, fabricaron los explosivos con formulas obtenidas a través de internet.

En el caso de la red del 11-M, la muestra de nuestro estudio incluye 19 manuales operativos. Sin embargo la mayor parte de ellos se dedican a teorizar sobre emboscadas, guerrillas, armas nucleares, etc. Es decir temáticas de escasa utilidad práctica que más bien cumplían un papel complementario al adoctrinamiento ideológico, contribuyendo a que se contemplasen a sí mismos como combatientes dentro de un nuevo tipo de guerra.

Entre los documentos analizados hay algunos que posiblemente les resultaron de mayor utilidad, sobre todo los procedentes de Al-Battar: una revista editada por al-Qaida en Arabia Saudí desde 2003 que tiene como fin proporcionar a distancia el adiestramiento especializado que recibían los alumnos de los campos de entrenamiento en Afganistán, antes de que fueran destruidos tras la intervención norteamericana en aquel país a finales de 2001 (Vidino, 2006, p. 79). Entre esos contenidos se encuentran, por ejemplo, algunos que hacen referencia a medidas de seguridad para no ser descubiertos y seguidos por la policía, con especial atención al uso de los teléfonos móviles.

Efectivamente, Serhane y otros de los miembros más expertos de la red tomaban numerosas precauciones en sus comunicaciones por teléfono cambiando varias veces de tarjeta de móvil en un mismo día o no utilizándolo en absoluto, limitándose al uso de cabinas públicas. Pero, sin embargo, esto no evitó que la investigación policial posterior a la masacre avanzara a pasos agigantados, gracias a algunas negligencias que los terroristas cometieron precisamente en el uso de los móviles. Su principal error consistió en utilizar para hacer llamadas telefónicas algunas tarjetas del mismo pack de las que fueron empleadas para fabricar las bombas. Cuando un Tedax logró desactivar a primeras horas del 12 de marzo uno de los explosivos de los trenes, la tarjeta permitió identificar el pack de procedencia y el rastro de las llamadas realizadas desde el resto de tarjetas. De ese modo la policía descubrió en cuestión de días la trama de venta de dinamita en Asturias, la casa de Morata de Tajuña (donde se fabricaron las bombas) y el piso que los terroristas habían alquilado en Leganés (donde se suicidó el núcleo central del comando). En términos generales el teléfono es el amigo más traicionero de los terroristas. Les resulta imprescindible por motivos prácticos pero son muchas las operaciones policiales que han tenido éxito gracias al control e interceptación de las comunicaciones telefónicas de los radicales.

Por otra parte, uno de los documentos hallados explica la fabricación de explosivo casero (conocido como TATP) que, por ejemplo, se utilizó en los atentados de Casablanca en mayo de 2003. Pero tampoco les resultó de gran ayuda ya que su fabricación requiere ciertos conocimientos expertos (un terrorista amateur puede provocar un incendio o una explosión a mitad del proceso de elaboración). En el portátil de un yihadista relacionado con los integrantes de la red, el egipcio Rabei Osman El Sayed, se encontró también una fotografía de una bomba activada con teléfono móvil. Sin embargo, la imagen no detallaba el modo como debían realizarse las conexiones. De esta manera continúa siendo un punto pendiente de aclarar por la investigación judicial cómo aprendieron a fabricar los artefactos explosivos utilizados en los trenes.

\section{Obtención de información operativa}

La facilidad de acceso a determinadas informaciones es otra de las grandes ventajas de internet desde el punto de vista de la planificación terrorista. Muchos atentados yihadistas se han dirigido contra "objetivos blandos", es decir, instalaciones con escasa o nula protección, como por ejemplo autobuses, trenes de metro, cafeterías, discotecas, hoteles, iglesias, sinagogas, etc. Se trata de lugares frecuentados, de acceso sencillo y en ocasiones con cierta carga simbólica. Por su propia lógica institucional o comercial ese tipo de objetivos ofrecen detalles concretos en sus webs sobre cómo llegar, horas de apertura, visita virtual, etc. Información que resulta de enorme valor a la hora de seleccionar posibles objetivos para cometer atentados.

Éste es un aspecto que también se refleja en el análisis de los ordenadores del 11-M. Existe constancia de que los terroristas visitaron después de la masacre de los trenes varias webs de instituciones judías en España, la mayor parte de ellas en Madrid o ciudades próximas como Ávila y Toledo. La dirección de uno de esos cen- 
tros judíos se encontró escrita en un papel descubierto entre los escombros del piso de Leganés. Lógicamente, si no hubieran sido localizados muy poco después por la policía, los terroristas se habrían visto obligados a realizar reconocimientos sobre el terreno antes atacar a alguno de dichos objetivos, pero sin duda internet les habría ayudado a descubrir y seleccionar el blanco idóneo y a saber cómo llegar hasta él.

\section{Comunicación privada}

La comunicación gratuita, en tiempo real y a cualquier distancia que ofrece internet también es un recurso ampliamente aprovechado (Jessee, 2006). El auto de procesamiento ofrece información interesante al respecto. Gracias al e-mail Moutaz Almallah Dabas y Serhane Abdelmajid mantenían contacto con Amer Azizi, un marroquí perteneciente a una célula de alQaida desarticulada en España en 2001 y que desde entonces se encuentra en paradero desconocido. La policía sospecha que Azizi puede estar escondido en Pakistán y en contacto con el núcleo central de al-Qai$d a$ en aquella región. Se desconoce el contenido de los e-mails que intercambiaron antes de los atentados pero no se puede descartar que el círculo más cercano a Bin Laden alentara o estuviera al corriente de que algo se estaba preparando en España gracias a esta vía de comunicación.

Por otro lado, alguno de los miembros de la red del 11-M participó en un grupo de Yahoo de contenidos radicales desde, al menos, febrero de 2003. El nombre del foro era Abu Banan Global Islamic Media. La policía no ha podido identificar quién de ellos estaba suscrito ni la dirección de e-mail que utilizaba, pero sí catorce documentos provenientes de dicho grupo en una memoria extraíble. A través de ese foro se hicieron circular dos documentos en diciembre de 2003 donde se aconsejaba atacar intereses españoles con el fin de desgastar al gobierno del Partido Popular, ante la proximidad de las elecciones, y facilitar de esta manera la victoria del Partido Socialista, y la consiguiente retirada de las tropas de Irak (Lia; Hegghammer, 2004). Aunque no se ha encontrado ninguno de ambos documentos en los ordenadores de los terroristas, lo más probable es que los recibieran a través de dicho grupo de Yahoo. Sin embargo, resulta difícil que esos materiales de diciembre de 2003 sirvieran de inspiración intelectual de los atentados, ya que está probado que la masacre comenzó a prepararse al menos desde

\footnotetext{
"El teléfono móvil es el amigo más traicionero de los terroristas"
}

principios de octubre de 2003 o, posiblemente, un poco antes: en el verano.

Por otra parte, también consta que un imputado por el 11-M, el marroquí Hassan el-Haski, se mantenía en contacto con otros yihadistas utilizando como medida de seguridad una misma cuenta de correo de Hotmail, en la que colgaban los distintos mensajes en la carpeta de "borrador".

\section{Comunicación pública}

Internet también se ha convertido en un instrumento de difusión de propaganda que hace innecesario someterse a la voluntad de los medios de comunicación a la hora de dar la noticia, y que entraña menos riesgos operativos si se toman precauciones para no dejar rastros electrónicos comprometedores en el servidor donde se cuelgan los archivos (Ulph, 2005). Además, las herramientas de software y el enorme volumen de documentos gráficos disponibles en el ciberespacio permiten que una persona con un mínimo de conocimientos pueda diseñar un producto propagandístico de calidad y con atractivo.

Entre los archivos encontrados en el análisis de los ordenadores del 11-M se encuentra la maqueta de un vídeo de reivindicación de los atentados de Madrid con fotografías de niños y mujeres heridos en Irak, escenas donde se ve a los presidentes Aznar y Bush, efectos de fusión de imágenes, y contenidos escritos en inglés y árabe deslizándose por la pantalla con una clara intención propagandística. Este documento puede encontrarse actualmente en YouTube.

http://www.youtube.com/watch? $v=c z G S y K d 3 S 7 s \&$ sea rch $=11 \mathrm{~m}$

\section{Seguimiento del impacto mediático}

Por último, la agilidad que internet proporciona a los medios de comunicación escritos a la hora de actualizar sus noticias y permitir su consulta continua también facilita que los terroristas sigan el impacto mediático y las consecuencias de sus acciones. El terrorismo (incluido el de inspiración yihadista) utiliza la violencia no como un fin en sí mismo, sino como instrumento de propaganda y chantaje. Por ello, la publicidad que reciben sus atentados y la respuesta ante el terror por parte de la sociedad y de los gobiernos resultan determinantes para su éxito o fracaso. De ahí su interés por el seguimiento informativo posterior.

Así se comprueba también en el análisis de los ordenadores de la red del 11-M. En ellos aparecen decenas de visitas y búsquedas de noticias referentes a los atentados, sobre todo en las webs de El país y de $E l$ mundo. Curiosamente, también se halla en uno de esos ordenadores el comunicado de un grupo yihadista fic- 
ticio Las brigadas de Abu Hafs al-Masri atribuyéndose los atentados de Madrid. Sería interesante saber qué comentaron entre sí los terroristas auténticos cuando vieron ese comunicado.

\section{Conclusiones}

El breve análisis realizado en estas páginas demuestra que internet supone un multiplicador de fuerzas para los yihadistas en el ámbito operativo. Evidentemente sin la ayuda de la Red también serían capaces de realizar sus actividades, pero la familiaridad con los ordenadores y la navegación virtual representan una ayuda más, especialmente para aquellos que no son terroristas veteranos ni han pasado por un campo de entrenamiento en Afganistán.

Pero la principal conclusión que se deduce de nuestro estudio - que coincide con otros trabajos similares de mayor profundidad (Paz, 2004, 2006; Rogan, 2006; Thomas, 2003; Ranstorp, 2004)- consiste en la importancia crucial de internet como medio de difusión libre de la doctrina y de la propaganda audiovisual yihadista. En este sentido, se ha convertido en uno de los pilares más relevantes donde se sustenta el movimiento ideológico transnacional denominado yihadismo global.

\section{Bibliografía}

Allievi, Stefano. "Islam in the public space: social networks, media and neo-communities". En: Allievi, Stefano; Nielsen, Jorgen. Muslim network and transnational communities in and across Europe. Boston: Brill Leiden, 2003, pp. 1-27. Isbn 9004128581 .

Burton, Fred. "The web of Jihad: strategic utility and tactical weakness". En: Stratfor.com, 13 June 2006.

Denning, Dorothy E. "Activism, hacktivism, and cyberterrorism: the internet as a tool for influencing foreign policy". En: Arquilla, John; Ronfeldt, David (editors). Networks and netwars: the future of terror, crime, and militancy. Santa Monica: RAND, 2001, pp. 239-288. Isbn 0-8330-3030-2.

Gunaratna, Rohan. "The post-Madrid face of Al-Qaeda". En: The Washington quarterly, 2004, v. 27, n. 3, pp. 91-100.

Jessee, Devin D. “Tactical means, strategic ends: Al Qaeda's use of denial and deception". En: Terrorism and political violence, 2006, v. 18, n. 3, pp. 367-388.
Josrojavar, Farhad. Los nuevos mártires de Alá. Madrid: Ediciones MR, 2003. Isbn 84-270-2978-0.

Kohlmann, Evan F. "The real online terrorist threat". En: Foreign affairs, 2006, Sept./Oct., v. 85 , n. 5, pp. 125-135.

Lia, Brynjar; Hegghammer, Thomas. "Jihadi strategic studies: the alleged Al Qaida policy study preceding the Madrid bombings". En: Studies in conflict \& terrorism, 2004, v. 27, n. 5, pp. 355-375.

Paz, Reuven. "The impact of the war in Iraq on islamist groups and the culture of global jihad". En: Conference on the impact of global terrorism at the International Policy Institute for Counter-Terrorism (ICT), 2004.

Paz, Reuven. Reading their lips: the credibility of jihadi web sites in arabic as a source for information. Consultado en: noviembre de 2006. http://www.e-prism.org/images/Read_Their_Lips.doc

Ranstorp, Magnus. "Al Qaeda en el ciberespacio: desafíos del terrorismo en la era de la información". En: Reinares, Fernando; Elorza, Antonio. El nuevo terrorismo islamista. Del 11-S al 11-M. Madrid: Temas de hoy, 2004. Isbn: 84-8460-373-3.

Rogan, Hanna. Jihadism online. A study of how al-Qaida and radical islamist groups use the internet for terrorist purposes. Kjeller: Norwegian Defence Research Establishment, 2006. Isbn 82-464-0999-9.

Sageman, Marc. Understanding terror networks. Philadelpia: University of Pennsylvania Press, 2004, Isbn 0-8122-3808-7.

Scheuer, Michael. Imperial hubris: why the West is losing the war on terror. Washington DC: Brassey's, 2004. Isbn: 1574888625.

Thomas, Timothy L. "Al Qaeda and the internet: the danger of 'cyberplanning'”. En: Parameters, 2003, Spring, v. XXXIII, n. 1, pp. 112-123.

Ulph, Stephen. "A guide to jihad on the web". En: Terrorism focus, 2005, March 31, v. II, n. 7

Vidino, Lorenzo. Al Qaeda in Europe. The new battleground of international jihad. New York: Prometeus Books, 2006. Isbn: 1591024331.

Weimann, Gabriel. Terror on the internet. The new arena, the new challenges. Washington DC: United States Institute of Peace Press, 2006. Isbn 1929223714.

Javier Jordán, Departamento de Ciencias Políticas y de la Administración, Universidad de Granada. jjordan@ugr.es

Manuel R. Torres, Universidad Pablo de Olavide, Sevilla.

mrtorsor@upo.es

\section{En MetaPress todo sigue igual}

Los suscriptores seguirán teniendo acceso online pdf y html a todo el período 2000-2007 en la web de MetaPress:

http://elprofesionaldelainformacion.metapress.com

MetaPress (empresa situada Alabama, EUA), del grupo Ebsco, es el mayor distribuidor de revistas-e (con clientes como Springer, Taylor \& Francis, IOS Press, etc.)

y dispone de complejos dispositivos de seguridad que garantizan la conservación

de EPI y un acceso perpetuo 24/7. 